\title{
Use of Preoperative Single Dose Ivabradine for Perioperative Hemodynamic Stabilization During Non-Cardiac Elective Surgery Under General Anaesthesia: A Pilot Study
}

\author{
Anwesha Banerjee ${ }^{a, b}$, Sangamitra Mishra ${ }^{a}$
}

\begin{abstract}
Background: Peri-anesthetic hemodynamic fluctuations during noncardiac surgeries are sometimes of serious consequences and associated with increased morbidity and mortality, especially in undiagnosed vulnerable patients. Currently used drugs like $\beta$-blocker, $\alpha 2$ agonist or sedative analgesic have their own limitations like combined negative ionotropic and chronotropic action, and unwanted bradycardia associated with hypotension, respectively. In this context, ivabradine has been used extensively in cases of cardiac failure, myocardial ischemia and cardiomyopathies for its funny channel associated dependable heart rate reducing property. Hence, for the first time, in search of a better agent for perioperative hemodynamic stabilization, the present study evaluated the role of ivabradine in patients undergoing non-cardiac surgeries.
\end{abstract}

Methods: This was a prospective, observer blind, randomized, interventional pilot study, conducted among 50 patients belonging undergoing elective abdominal laparoscopic surgeries, under general anesthesia. The study group patients received ivabradine tablet $7.5 \mathrm{mg}, 2$ $\mathrm{h}$ before scheduled time of surgery with a sip of water. All the patients received standardized balanced general anesthesia as practiced in our institute with all standard monitoring with additional minimum alveolar concentration (MAC) monitoring to ensure an adequate depth of anesthesia, and neuromuscular monitoring to ensure adequate and standard muscle relaxation. Hemodynamic stability of the groups was tested by comparing them at time points like induction, incision and operation, and extubation. Mean values of heart rate (HR), systolic blood pressure (SBP), diastolic blood pressure (DBP) and mean arterial pressure (MAP) were compared between groups, and also for variation with lapse of time, using RMANOVA analysis, using baseline parameters as covariate so as to standardize them.

Results: On multivariate analysis using Wilk's lambda multivariate test, there was a statistically significant difference $(\mathrm{F}=3.587, \mathrm{P}=$

Manuscript submitted February 4, 2021, accepted May 29, 2021

Published online June 25, 2021

aDepartment of Anesthesia and Critical Care, IMS and Sum Hospital, Siksha O'Anusandhan, Bhubaneswar, Odisha 751003, India

${ }^{b}$ Corresponding Author: Anwesha Banerjee, Department of Anesthesia and Critical Care, IMS and Sum Hospital, Siksha O'Anusandhan, Bhubaneswar, Odisha 751003, India. Email: anwesha2801@gmail.com

doi: https://doi.org/10.14740/jocmr4441
0.036) in HR between the groups with time, while no significant difference of SBP, DBP and MAP between the groups with time.

Conclusions: The study revealed a significant attenuation of HR response to stressful events like laryngoscopy, intubation and surgical incision with ivabradine. Also, a good intraoperative protection against cardiovascular ischemic and arrhythmic episodes in perioperative period was achieved with this drug ivabradine.

Keywords: Ivabradine; Peri-anesthetic; Hemodynamic fluctuations; Laryngoscopy; Intubation

\section{Introduction}

Anesthesia course is not free from hemodynamic fluctuations, mostly due to stress response during laryngoscopy, endotracheal intubation, surgical stimulation, awareness during extubation, and recovery from anesthesia, which often lead to tachycardia and hypertension [1]. Peri-anesthetic hemodynamic fluctuations during non-cardiac surgeries are sometimes of serious consequences and associated with increased morbidity and mortality, especially in undiagnosed vulnerable patients [2]. Various strategies have been used to attenuate these stress responses in high risk individuals. Currently perioperative administrations of $\beta$-blockers and $\alpha 2$ agonist are the established therapeutic options. $\beta$-blockers like metoprolol, though effective for hemodynamic stabilization, its combined negative ionotropic and chronotropic action may raise the possibility of obtunding compensatory physiological mechanisms at the time of perioperative period, i.e., during surgical bleeding or low systemic vascular resistance (SVR) conditions related to anesthesia [3, 4].

Clonidine, a centrally acting $\alpha 2$ agonist, used predominantly as antihypertensive, usually in combination with other agents, has not been a first choice of drug due to its serious complications of acute withdrawal syndrome with rebound hypertension because of intrathecal pump malfunction $[5,6]$.

Till recently, ivabradine has been used extensively in cases of cardiac failure $[7,8]$, myocardial ischemia $[9,10]$ and cardiomyopathies $[11,12]$ for its dependable heart rate (HR) reducing property $[13,14]$. Ivabradine induces HR reduction by selective sinus node (SAN) inhibition. Its role in perioperative hemodynamic stabilization has not been evaluated during non- 
cardiac surgery. Hence, in search of a better agent for perioperative hemodynamic stabilization, in the present study the role of ivabradine in patients undergoing non-cardiac surgeries was evaluated. The study was designed as a randomized, interventional pilot study in order to reduce bias and to remark the changes due to treatment [15]. The perioperative period undergoes dramatic hemodynamic stress responses leading to tachycardia and hypertension increasing myocardial oxygen demand $[16,17]$. Laryngoscopy and intubation are potent stimuli for increase in HR and blood pressure (BP), recognized since 1951 [18]. The mechanism of hemodynamic response to laryngoscopy and intubation is proposed to be by sympathetic reflex provoked by stimulation of larynx [19].

Stimulation of proprioceptors at the base of tongue during laryngoscopy induces impulse dependent increases of BP, HR and plasma catecholamine concentrations. Subsequent intubation recruits additional receptors that elicit augmented hemodynamic and epinephrine responses, as well as some vagal inhibition of heart. Intubation also has effect on electrocardiograph which was of the nature of premature ventricular beat [20], nodal rhythm, and sinus bradycardia [21-23].

These changes might be of little consequence in healthy patients, but in patients with hypertension [24], ischemic heart disease, cardiac failure, increased intracranial pressure or aneurysmal vascular disease strict control of hemodynamic stress response is necessary for a better patient outcome [25]. Cardiovascular stress response to laryngoscopy may complicate into acute left ventricular failure [26], arrhythmias, intracranial hemorrhage and pulmonary edema [27]. Measurements of the plasma catecholamine have demonstrated an increase in noradrenaline following laryngoscopy and thus confirmed sympathetic stimulation.

There have been numerous techniques employed to modify pressor response with varying success; for example, procaine chloride had been used to bring down the incidence of cardiac arrhythmias; diethylaminoethanol was found to reduce the occurrence of electrocardiography (ECG) abnormalities successfully; regional and topical analgesia have been used to block different impulses; and intravenous lidocaine and deeper inhalational anesthesia have been used to modify response at central nervous system level. Many other methods advocated are $\beta$-adrenergic receptor blocker, $\alpha$-adrenergic agonists, calcium channel blockers, and intravenous nitroglycerine [28].

$\beta$-blockers by binding to $\beta$-adrenoreceptors of sinoatrial node attenuate the endogenous sympathetic chronotropic effect, thus showing negative chronotropic effect. It also binds to $\beta$-receptors of many other cells, leading to not only negative chronotropic effect but also negative inotropic effects on the heart and other organs [29]. The analysis showed $\beta$-blockers do not reliably decrease HR and may be associated with increased side effects [30].

$\alpha 2$ agonist, dexmedetomidine, is a good adjuvant that decreases the requirement of anesthetics and opioids, attenuates sympathoadrenal response, maintains the stable hemodynamics; but its exuberant cost, excessive sedation along with unwanted bradycardia associated with hypotension makes it a poor agent of choice [31].

In addition, laparoscopic surgery and pneumoperitoneum induce further stress response. There have been evidences of increased plasma level of catecholamine and vasopressin on intraperitoneal insufflation with carbon dioxide for pneumoperitoneum. Elevation of intra-abdominal pressure with raised diaphragm causes various adverse effects such as decreased cardiac output, elevated arterial pressure and increased systemic and pulmonary vascular resistance leading to hypertension and tachycardia [32]. Therefore, this study was conducted in patients undergoing non-cardiac, laparoscopic surgeries.

Hence, drug which can blunt hemodynamic responses to laryngoscopy, intubation and pneumoperitoneum without having any adverse effects like respiratory depression and postoperative nausea and vomiting (PONV) is essential. Ivabradine is a very unique drug in medical literature. It is a first intrinsic cardiac funny current inhibitor I(f), inhibiting the pacemaker activity of the SAN, clinically successful in reducing HR without jeopardizing hemodynamic in unhealthy patients [33]. The drug can be used not only in hypertensives but also in normotensives and patients with asthma where $\beta$-blockers are contraindicated $[17,34]$. In the present study, normotensive, American Society of Anesthesiologists (ASA) grade 1 patients were included.

Ivabradine is well absorbed orally from gastrointestinal tract and within 20 - 30 min, with peak plasma concentration attained by 60 - 90 min $[14,35,36]$. Clinical studies demonstrate that ivabradine is effective in reducing HR at rest and during stress [37]. The rationale of this study was to minimize perioperative stress response using therapeutic dose of ivabradine. It was hypothesized that addition of single dose ivabradine to standard general anesthetic technique results in better hemodynamic control in patient undergoing non-cardiac surgery. Therefore, the study was aimed to evaluate the role of preoperative single dose oral ivabradine for perioperative hemodynamic control during elective non-cardiac surgery under general anesthesia.

\section{Materials and Methods}

This was designed as prospective, observer blind, randomized, interventional pilot study. It was conducted in Department of Anesthesiology, Institute of Medical Sciences and SUM Hospital, Bhubaneshwar, from November 2017 to August 2018. Institutional ethics committee (IEC) approval was obtained before the commencement of study. The study was registered prospectively with CTRI on November 15, 2017 (registration number: REF/2017/10/015572); and was conducted in compliance with the ethical standards of the responsible institution on human subjects as well as with the Helsinki Declaration. Being a pilot study a sample size of 25 in each group namely C (control group) and I (ivabradine group) was chosen deliberately by random number allocation technique. Written informed consent was taken from each patient in both of the groups after they were provided with a detailed information sheet for participating in the study.

\section{Inclusion criteria}

Adult patients belonging to ASA grade 1 status, posted for 
elective abdominal laparoscopic surgeries of estimated $2-4 \mathrm{~h}$ duration were included in the study.

\section{Exclusion criteria}

The following exclusion criteria were considered for sample selection: 1) Anticipated difficult airway; 2) Patients with history of any medication or substance abuse; 3) Age $<18$ years or $>50$ years; 4) Weight $<40 \mathrm{~kg}$ or $>70 \mathrm{~kg}$; 5) Height $<150$ $\mathrm{cm}$ or $>180 \mathrm{~cm}$; 6) Baseline HR: $\leq 60 \mathrm{bpm}$ or $\geq 90 \mathrm{bpm}$; 7) Baseline $\mathrm{BP} \leq 90 / 50 / 65 \mathrm{~mm} \mathrm{Hg}$ or $\geq 140 / 85 / 105 \mathrm{~mm} \mathrm{Hg}$; 8) Peak airway pressure $>35 \mathrm{cmH}_{2} \mathrm{O}$ or mean airway pressure $>$ $30 \mathrm{cmH}_{2} \mathrm{O}$ constantly for $>5 \mathrm{~min}$; 9) $>1$ min for laryngoscopy and intubation; 10) $>1$ attempt at extubation or $>5$ min of suction and extubation attempt; 11) Intraoperative heavy bleeding (obscured field due to bleeding and in spite of continuous suction and cautery use for $>5 \mathrm{~min}$.

\section{Methodology}

The study was conducted among 50 ASA grade 1 adult patients belonging to both sexes and of age group between 18 - 50 years, undergoing elective abdominal laparoscopic surgeries, under general anesthesia. The patients, as well as the anesthesiologist and perioperative sisters who monitored the patients, were blinded to the groups. Only the study group patients, i.e., group I patients received ivabradine tablet $7.5 \mathrm{mg}, 2 \mathrm{~h}$ before scheduled time of surgery with a sip of water.

Perioperatively all patients were monitored with standard ASA monitors, i.e., $\mathrm{HR}$, pulse oximetry $\left(\mathrm{SPO}_{2}\right)$, non-invasive $\mathrm{BP}, \mathrm{ECG}$ and temperature. In addition to that end tidal carbon dioxide $\left(\mathrm{ETCO}_{2}\right)$, urine output (UO), temperature, minimum alveolar concentration (MAC) for inhaled anesthetics, neuromuscular monitoring (NMT): train-of-four (TOF) count, intrathoracic pressure (mean and maximum), tidal volume (TV), minute ventilation (MV), peak airway pressure (PAW), intraabdominal pressures, and total blood loss were to be monitored. All these parameters were recorded to standardize the anesthesia technique and depth of anesthesia.

Perioperative period would be defined as: from $15 \mathrm{~min}$ before induction of anesthesia till $10 \mathrm{~min}$ of extubation or till patient is awake and oriented whichever is later.

Baseline HR and baseline BP were defined as the respective $\mathrm{HR}$ and $\mathrm{BP}$ recorded by the ward sister during the nonrapid eye movement (NREM) phase of sleep, the night before surgery.

Perioperative hemodynamic events were defined as follows: bradycardia ( $\leq 60$ beats/min), absolute bradycardia ( $\leq$ 50 beats/min), tachycardia ( $\geq 90$ beats/min), hypotension ( $\leq$ 90/50/65 mm Hg), hypertension ( $\geq 140 / 85 / 105 \mathrm{~mm} \mathrm{Hg}$ ), arrhythmias (any non-sinus rhythm in absence of cautery interference), ischemic changes $(>/<2 \mathrm{~mm}$ changes in ST).

As per institutional protocol, all the patients received standardized balanced general anesthesia as described below, and as practiced in our institute with all standard monitoring with additional MAC monitoring to ensure an adequate depth of anesthesia and neuromuscular monitoring to ensure adequate and standard muscle relaxation.

\section{Pre-anesthetic check-up}

A complete pre-anesthetic check-up was done for all patients; a detailed history was taken, and complete physical examination was done. Investigations, namely complete blood count, serum electrolytes, blood urea, serum creatinine, viral markers (human immunodeficiency virus (HIV), hepatitis B surface antigen (HBsAg), and hepatitis $\mathrm{C}$ virus (HCV)) and ECG were done for all the patients. Any other investigation was done as per requirement.

All the patients were assessed clinically preoperatively, and presence of any medical comorbidity was excluded from the study. Patients with history of drug abuse, history of chest pain, history of palpitations, syncope, respiratory or cardiac conditions, hepatic or renal dysfunction were excluded from the study.

\section{Preoperative}

Preoperatively both the groups, namely I (ivabradine group) and $\mathrm{C}$ (control group) received their overnight premedication drugs (i.e., tablet famotidine $40 \mathrm{mg}$ and tablet Ativan $1 \mathrm{mg}$, for $<50 \mathrm{~kg}$, and $2 \mathrm{mg}>50 \mathrm{~kg}$ ) with a sip of water. The I group patients also received tablet ivabradine, $7.5 \mathrm{mg}, 2 \mathrm{~h}$ before surgery with a sip of water.

\section{Intraoperative}

In operation theatres, at time of induction all the patients received intravenously injection of midazolam $(0.03 \mathrm{mg} / \mathrm{kg})$, Themiset $(0.75 \mathrm{mg})$, fentanyl $(2 \mu \mathrm{g} / \mathrm{kg})$, diclofenac $(1 \mathrm{mg} /$ $\mathrm{kg}$ ) and ranitidine $(50 \mathrm{mg})$. Patients were preoxygenated with $100 \%$ oxygen with mask for 2 min. Injection of vecuronium $(0.1 \mathrm{mg} / \mathrm{kg})$ was given intravenously, followed by assisted mask ventilation with $100 \%$ oxygen till induction of anesthesia. Muscle relaxation was noted with TOF monitoring. Induction of patients with titrated dose of injection of propofol over 1 min till loss of verbal contact was carried out. After induction with propofol isoflurane was switched on with dial setting 5 with fresh gas flow of $6 \mathrm{~L}\left(1.5 \mathrm{~L}\right.$ oxygen $\left(\mathrm{O}_{2}\right), 1.5 \mathrm{~L}$ air, $3 \mathrm{~L}$ nitrous oxide $\left(\mathrm{N}_{2} \mathrm{O}\right)$ ). Gradually the dial setting was reduced to achieve a MAC value of 1.2. Muscle relaxation was monitored by TOF count. When TOF count became 0 and MAC value became 1.2 short duration $(<45 \mathrm{~s})$ laryngoscopy and intubation was attempted. The cases where $>2$ min was taken for laryngoscopy and intubation or $>1$ attempt was required were excluded from the study. After intubation isoflurane dial setting was titrated to keep MAC at $0.6-0.8 \%$ with a low gas flow $\left(\mathrm{N}_{2} \mathrm{O}: 0.4 \mathrm{~L}, \mathrm{O}_{2}: 0.2 \mathrm{~L}\right.$, air: $\left.0.25 \mathrm{~L}\right)$. Maintenance of anesthesia was achieved with $\mathrm{N}_{2} \mathrm{O}$, air and $\mathrm{O}_{2}$ in equal parts plus isoflurane (in concentration of $0.8-1.0 \%$, to maintain a MAC of $0.6-0.8 \%$ throughout surgery) in a ratio of $1: 1: 1$ with fresh 
gas flow of $0.5 \mathrm{~L}$ each. Intraoperative TOF count of 1 - 2 was maintained, with muscle relaxant injection of vecuronium, intermittent dose $(0.02 \mathrm{mg} / \mathrm{kg})$ given when TOF became 3 . Intravenous isotonic crystalloid (normal saline (NS)/Ringer's lactate (RL)) was administered according to 4-2-1 rule and additionally according to blood loss $(2 \mathrm{~mL} / \mathrm{kg} / \mathrm{h}$ for mild loss, 4 $\mathrm{mL} / \mathrm{kg} / \mathrm{h}$ for moderate loss and $6 \mathrm{~mL} / \mathrm{kg} / \mathrm{h}$ for severe loss).

\section{Ventilatory parameters were adjusted for all patients accord-} ingly

TV $6-8 \mathrm{~mL} / \mathrm{kg}$ (based on ideal body weight (IBW) MV was titrated to keep a $\mathrm{ETCO}_{2}$ of $35-45 \mathrm{~mm} \mathrm{Hg}$. Intraoperatively HR, non-invasive blood pressure (NIBP), MAC, TOF, temperature (nasopharyngeal), UO, blood loss (mild/moderate/ severe) and ventilator parameters (TV, expiratory tidal volume $\left(\mathrm{V}_{\mathrm{TE}}\right)$, minute ventilation $(\mathrm{VE}), \mathrm{P}_{\max }, \mathrm{P}_{\text {mean }}$, respiratory rate $(\mathrm{RR})$, inspiratory/expiratory ratio (I:E ratio), positive end expiratory pressure (PEEP), and plateau pressure) were monitored.

\section{Blood loss}

Blood loss was defined as: 1) Mild blood loss: only oozing consensus with both anesthetist and surgeon; 2) Moderate blood loss: sprouting blood vessels off and on with cautery required to seal the vessel; 3) Severe blood loss: bleeding covering and blurring surgical field with surgeon requiring using cautery consistently and using suction to clear field. Patient developing severe blood loss for more than 10 min were excluded from the study.

For all surgeries bipolar electrocoagulation was used to ensure minimal blood loss. If any patient develops hypotension $<30 \%$ of baseline during surgery or mean arterial pressure (MAP) $<65 \mathrm{~mm} \mathrm{Hg}$, patient was treated with Trendelenburg position and rapid intravenous fluid administration. If BP did not improve in $5 \mathrm{~min}$, then intravenous injection of ephedrine $2.5 \mathrm{mg}$ (if $\mathrm{HR}<60 \mathrm{bpm}$ ), or intravenous injection of phenylephrine $25 \mu \mathrm{g}$ (if HR $>60 \mathrm{bpm}$ ) were tried, and vasopressors doses were repeated if BP still remained below 30\% of baseline recording.

Injection of fentanyl $(0.5 \mu \mathrm{g} / \mathrm{kg})$ was repeated every 45 min to maintain adequate analgesia. An additional dose of injection of fentanyl $(0.1 \mu \mathrm{g})$ was repeated before extubation if last dose was given $>30 \mathrm{~min}$ before.

\section{Postoperative}

For postoperative analgesia $40 \mathrm{~mL} 0.125 \%$ of bupivacaine was infiltrated through port intra-abdominally, and also all ports were infiltrated at end of surgery with $2 \mathrm{~mL}$ of $0.125 \%$ of bupivacaine.

At the end of surgery, oropharyngeal suction was carried out when patient was still under MAC of 0.6-0.8\%. Extubation was carried out at MAC 0, expired fractional $\mathrm{N}_{2} \mathrm{O}<10 \%$ and isoflurane $<0.1 \%$, TOF count 1 st: 4 th twitch height $75 \%$. Patient was reversed with Myo-pyrolate (neostigmine $0.05 \mathrm{mg}$ / $\mathrm{kg}$ and glycopyrrolate $0.2 \mathrm{mg}$ ). Oxygen supplementation was continued till $\mathrm{N}_{2} \mathrm{O}$, and isoflurane concentration in expired air is $0 \%$.

Parameters were recorded every $5 \mathrm{~min}$ during perioperative period with special emphasis to the period of following, when parameters were recorded every 1 min till 5 min of procedures, i.e., laryngoscopy and intubation, skin incision, extubation and recovery from anesthesia.

Parameters recorded were: HR, systolic blood pressure (SBP), diastolic blood pressure (DBP), MAP, arrhythmia (any non-sinus rhythm), and ischemia (ST changes $>/<2 \mathrm{~mm}$ ). lyzed.

Any other adverse events were also recorded and ana-

\section{Statistical analysis}

Results obtained from the study were expressed in tabular form in the following section. Numeric data have been expressed as mean \pm standard deviation (SD).

For intra-group comparison (at the same time point, between the groups), Student's $t$-test was applied. A P value $<$ 0.05 was considered as statistically significant, and $<0.01$ as highly significant. The software SPSS (version 20.0) was used for analysis.

\section{Results}

The mean age of the two study groups were 42.4 years with a SD of 12.75 for ivabradine, and 38.84 years with a SD of 6.95 ; and there was no significant difference observed between these groups. Similarly, gender distribution was found to be similar between the comparison groups $\left(\chi^{2}=0.439\right.$ using Chi-square test, $\mathrm{P}$ value $=0.508$, non-significant, Table 1 ). Thus, groups were comparable with respect to age and gender. The mean levels of HR for treatment group (with ivabradine) was found to be 83.4 with a SD of 10.24, while that of control group not receiving ivabradine was found to be 82.24 with a SD of 12.44 (Table 2). The groups were comparable with respect to baseline HR $(\mathrm{P}>0.05)$.

The mean levels of SBP, DBP and MAP for treatment group was found to be $128.6,81.00$ and 96.87 with SD of $15.27,8.93$ and 10.00 , respectively, while for that of the control group it was found to be 124.32, 80.12 and 94.85 with SD of $13.33,6.23$ and 7.63 , respectively. The groups were comparable with respect to baseline SBP $(\mathrm{P}>0.05)$, baseline DBP $(\mathrm{P}$ $>0.05)$ and $\operatorname{MAP}(\mathrm{P}>0.05$, Table 2$)$.

Other parameters like ECG changes (ST elevation or depression) and occurrence of arrhythmia were not present in both groups, and hence were comparable.

The hemodynamic stability during perioperative vulnerable period was observed during the first $5 \mathrm{~min}$, every minute during intubation, incision and operation, and extubation. During the time of intubation, incision and surgery significant difference in proportion of cases of ivabradine having change in 
Table 1. Gender Distribution Among the Study Participants ( $=25$ for Each Group)

\begin{tabular}{|c|c|c|c|}
\hline & \multicolumn{2}{|c|}{ Group of patients } & \multirow{2}{*}{ Total } \\
\hline & Ivabradine & Control & \\
\hline \multicolumn{4}{|l|}{ Male } \\
\hline Expected count & 6.0 & 6.0 & 12.0 \\
\hline$\%$ within gender & $41.7 \%$ & $58.3 \%$ & $100.0 \%$ \\
\hline Expected count & 19.0 & 19.0 & 38.0 \\
\hline$\%$ within gender & $52.6 \%$ & $47.4 \%$ & $100.0 \%$ \\
\hline \multicolumn{4}{|l|}{ Total } \\
\hline Count & 25 & 25 & 50 \\
\hline
\end{tabular}

HR, SBP, DBP and MAP more than $20 \%$ as compared to the controls was considered (Table 3). Twenty percent of cut-off was decided after detailed consideration of results of multiple similar studies [38-41] on correlation with baseline data and calculating the mean. On the other hand, during extubation no significant difference was observed between ivabradine group and control group in terms of hemodynamic instability (Table $4)$. The hemodynamic changes during entire duration of operation are depicted in Table 5.

Mean HR during incision and operative hours were categorized into groups based on whether there was bradycardia $(<60)$, normal $(60-90)$ or tachycardia (90 or more). It was seen that incidence of tachycardia was more among control group (10 cases, 40\%, Table 6). Cross-tabulation showed that there is a statistically significant association of type of intervention (ivabradine vs. control) with HR (likelihood ratio = 8.541, $\mathrm{P}=0.014$; using Chi-square tests). Mean values of SBP, DBP and MAP during incision and operative hours were used for categorizing into groups of hypotension $(<90 / 50 / 65)$ and hypertension $(>140 / 85 / 105)$. There was no association of BP category with type of intervention as observed during crosstabulation using Chi-square test $(\mathrm{P}=0.733$, not significant, Table 7).

Hemodynamic stability of the groups was tested by com- paring them at time points like induction, incision and operation, and extubation. Mean values of HR, SBP, DBP and MAP were compared between groups, and also for variation with lapse of time, using RMANOVA analysis, using baseline parameters as covariate so as to standardize them.

On multivariate analysis using Wilk's lambda multivariate test, there was a statistically significant difference $(F=3.587$, $\mathrm{P}=0.036$ ) in HR between the groups with time (Fig. 1) [1-3], while no significant difference of the SBP, DBP and MAP between the groups with time (Wilk's lambda multivariate test; F $=0.049, \mathrm{P}=0.952$, (Figs. 2-4) [1-3]).

\section{Discussion}

The current study was designed with an aim of evaluation of the role of preoperative single dose oral ivabradine for perioperative hemodynamic stabilization in patients undergoing elective non-cardiac surgery under general anesthesia. Hemodynamic stability as defined by Dutton RP, as the physiological state whereby adequate blood flow to and perfusion of organ is achieved [42]. This reflex transient hemodynamic stress response includes rise in HR and BP, can lead to life-threatening complications in patients with cardiovascular and cerebral dis-

Table 2. Baseline Hemodynamic Parameters of the Study Participants ( $N=25$ Each)

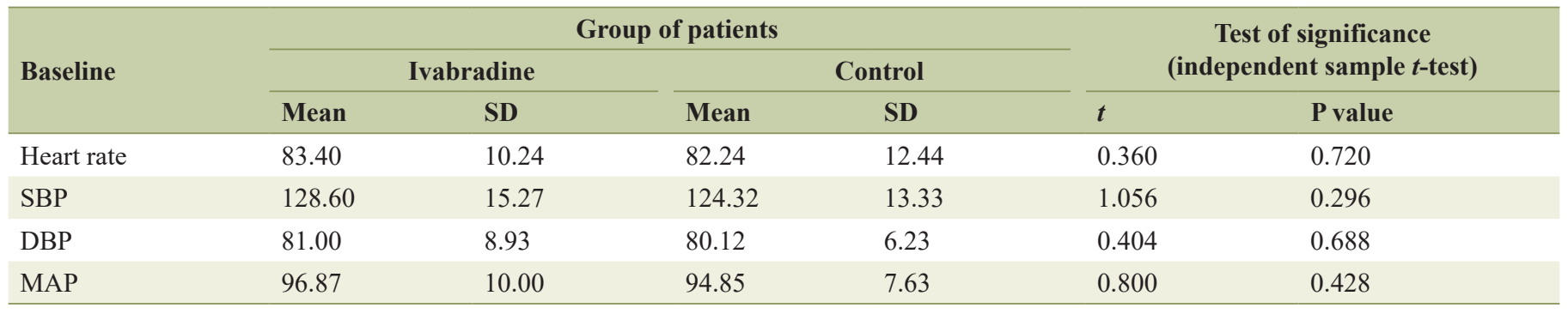

SBP: systolic blood pressure; DBP: diastolic blood pressure; MAP: mean arterial pressure; SD: standard deviation. 
Table 3. Change in Hemodynamic Parameters Beyond $20 \%$ of Baseline ( $N=25$ Each) During Intubation, Incision and Operation

\begin{tabular}{|c|c|c|c|c|}
\hline & \multicolumn{4}{|c|}{ Group of patients } \\
\hline & \multicolumn{2}{|c|}{ Ivabradine } & \multicolumn{2}{|c|}{ Control } \\
\hline & Count & $\%$ & Count & $\%$ \\
\hline \multicolumn{5}{|l|}{ Amount of change in HR } \\
\hline Decrease $>20 \%$ & 0 & $0.0 \%$ & 3 & $12.0 \%$ \\
\hline \multicolumn{5}{|l|}{ Amount of change in SBP } \\
\hline Decrease $>20 \%$ & 2 & $8.0 \%$ & 2 & $8.0 \%$ \\
\hline Change within $20 \%$ & 20 & $80.0 \%$ & 20 & $80.0 \%$ \\
\hline Increase $>20 \%$ & 3 & $12.0 \%$ & 3 & $12.0 \%$ \\
\hline Increase $>20 \%$ & 5 & $20.0 \%$ & 4 & $16.0 \%$ \\
\hline \multicolumn{5}{|l|}{ Amount of change in MAP } \\
\hline Decrease $>20 \%$ & 3 & $12.0 \%$ & 2 & $8.0 \%$ \\
\hline Change within $20 \%$ & 20 & $80.0 \%$ & 19 & $76.0 \%$ \\
\hline \multicolumn{5}{|c|}{ Change during incision and operation } \\
\hline \multicolumn{5}{|c|}{ Amount of change in HR } \\
\hline Decrease $>20 \%$ & 4 & $16.0 \%$ & 11 & $44.0 \%$ \\
\hline Change $<20 \%$ & 19 & $76.0 \%$ & 10 & $40.0 \%$ \\
\hline Increase $>20 \%$ & 2 & $8.0 \%$ & 4 & $16.0 \%$ \\
\hline Change $<20 \%$ & 16 & $64.0 \%$ & 14 & $56.0 \%$ \\
\hline Increase $>20 \%$ & 2 & $8.0 \%$ & 4 & $16.0 \%$ \\
\hline \multicolumn{5}{|l|}{ Amount of change in MAP } \\
\hline Decrease $>20 \%$ & 9 & $36.0 \%$ & 9 & $36.0 \%$ \\
\hline Change $<20 \%$ & 14 & $56.0 \%$ & 15 & $60.0 \%$ \\
\hline Increase $>20 \%$ & 2 & $8.0 \%$ & 1 & $4.0 \%$ \\
\hline
\end{tabular}

HR: heart rate; SBP: systolic blood pressure; DBP: diastolic blood pressure; MAP: mean arterial pressure.

eases. In 1951, King et al described the sympathetic stress response to laryngoscopy and intubation [18]. In 1977, series of studies concluded that stress responses in anesthetized patients may be more hazardous in patients of hypertension, myocardial insufficiency or cerebrovascular diseases [35].

There has been tremendous advancement is field of anesthesia since then, leading to a drastic improvement in clinical practice and outcome. Furthermore, research is still continu- ing; and this study was conducted in order to suggest an agent for attenuation of perioperative hemodynamic stress response, which would be better than those already existing. Ivabradine has emerged has a good agent in HR control in heart failure and improvement in patient outcome, as demonstrated in the SHIFT trial [43]. The INITIATIVE study results indicated that ivabradine is as effective as atenolol in lowering HR in patient with stable angina pectoris. 
Table 4. Change in Hemodynamic Parameters Beyond $20 \%$ of Baseline ( $N=25$ Each) During Extubation

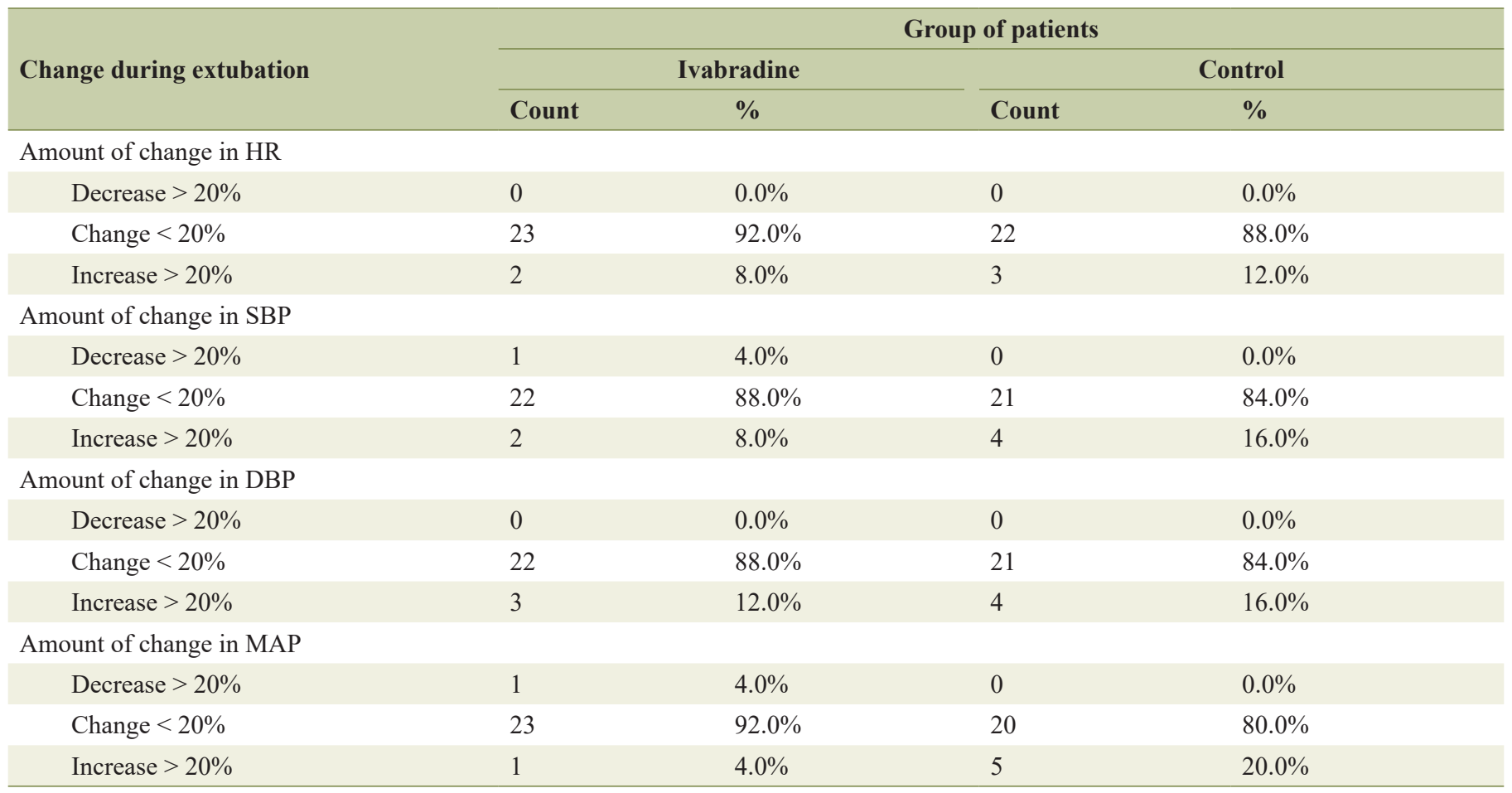

HR: heart rate; SBP: systolic blood pressure; DBP: diastolic blood pressure; MAP: mean arterial pressure.

In present study, oral ivabradine for stabilization of hemodynamic stress response to laryngoscopy and intubation, surgical incision and extubation have been evaluated. BP (SBP, DBP and MAP) and HR were taken as the main parameters to be compared. In addition to that ECG changes (ST changes, rhythm changes) were noted to account for any arrhythmic or ischemic episodes. The additional parameters were recorded in order to minimize bias and standardize a similar plane of anesthesia and physiological conditions for all patients participating in the study.

The baseline parameters were recorded the night before surgery when patients were in their NREM sleep. Pre-induction parameters showed slight increase in HR and BP as compared to baseline parameters. After induction, at the time of laryngoscopy and intubation the parameters were recorded followed by at every 1-min interval till $5 \mathrm{~min}$; thereafter, parameters were recorded at every $5 \mathrm{~min}$. Again, at the time of incision and extubation special emphasis were given and the parameters were recorded at every 1-min interval till $5 \mathrm{~min}$. The period of laryngoscopy and intubation were taken as a coinciding event and also period of extubation and recovery from anesthesia.

In our study, in test group (group I), there was not very significant increase in hemodynamic parameters in response to laryngoscopy and intubation, incision and extubation when compared to control group (group C); and minimal raise also returned to near baseline immediately within a minute. In control group, the increase in hemodynamic response at defined periods were significantly higher, especially HR was significantly on a higher side in the control group. It was found that mean age of two study groups were 42.4 years with SD of 12.75 for ivabradine, and 38.84 years with SD of 6.95 , and there was no significant difference observed between these groups. Similarly, gender distribution was found to be similar

Table 5. Comparison of Total Change in Hemodynamic Stability (From Baseline Till End of Observation Period of Extubation) Among the Study Groups ( $=25$ Each)

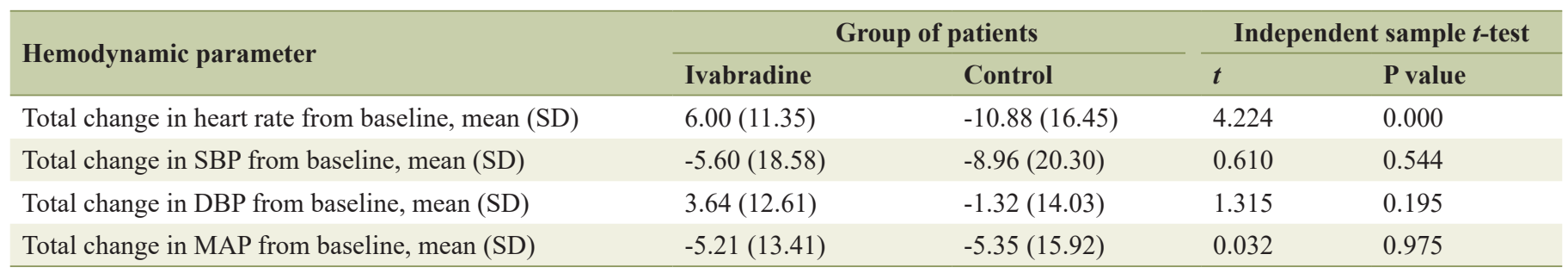

SD: standard deviation. 
Table 6. Incidence of Bradycardia and Tachycardia Among the Study Participants ( $=25$ Each)

\begin{tabular}{|c|c|c|c|}
\hline & \multicolumn{2}{|c|}{ Group of patients } & \multirow{2}{*}{ Total } \\
\hline & Ivabradine & Control & \\
\hline \multicolumn{4}{|l|}{ Bradycardia } \\
\hline Expected count & 0.5 & 0.5 & 1.0 \\
\hline$\%$ within group & $4.0 \%$ & $0.0 \%$ & $2.0 \%$ \\
\hline Expected count & 18.5 & 18.5 & 37.0 \\
\hline$\%$ within group & $88.0 \%$ & $60.0 \%$ & $74.0 \%$ \\
\hline \multicolumn{4}{|l|}{ Tachycardia } \\
\hline Count & 2 & 10 & 12 \\
\hline Count & 25 & 25 & 50 \\
\hline Expected count & 25.0 & 25.0 & 50.0 \\
\hline$\%$ within group & $100.0 \%$ & $100.0 \%$ & $100.0 \%$ \\
\hline
\end{tabular}

between the comparison groups $\left(\chi^{2}=0.439\right.$ using Chi-square test, $\mathrm{P}$ value $=0.508$, not significant). Thus, the groups were comparable with respect to age and gender.

Hemodynamic stability was observed during the first 5 min, every minute during intubation, incision and operation, and extubation. Significant difference in proportion of cases of ivabradine having change in HR more than $20 \%$ was observed as compared to controls, while not much significant difference in proportion of cases of ivabradine having change in SBP, DBP, MAP more than $20 \%$ as compared to controls. No significant difference was observed between ivabradine group and control group in terms of hemodynamic instability during extubation.

Also, significant difference in the total change in HR from baseline was seen among ivabradine group $(\mathrm{P}=0.000)$ as compared to the controls, while not much significant difference in total change in SBP, DBP, MAP from baseline among the two groups. Mean HR during incision and surgery were categorized into groups based on whether there was bradycardia $(<$ $60)$, normal (60 - 90) or tachycardia (90 or more). It was seen that incidence of tachycardia was more among control group (10 cases, $40 \%$ ). Cross-tabulation showed that there is a statis-

Table 7. Incidence of Blood Pressure Among the Study Participants ( $N=25$ Each)

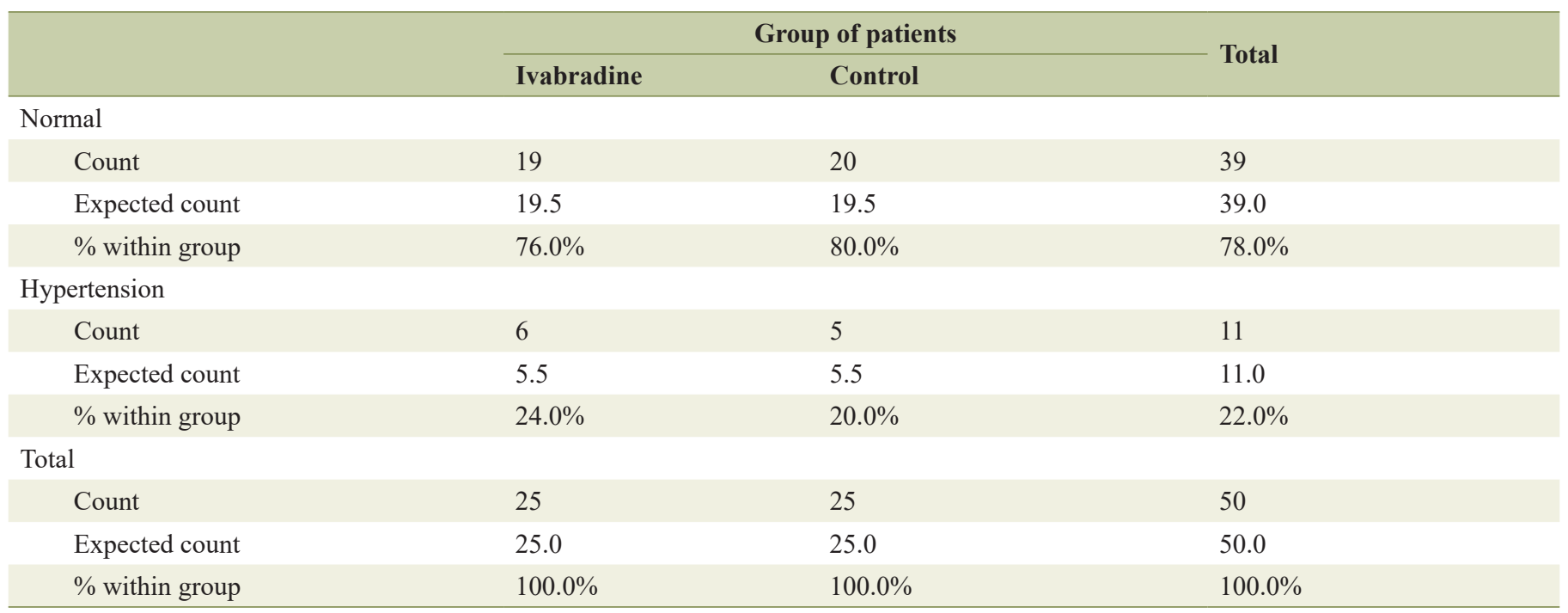




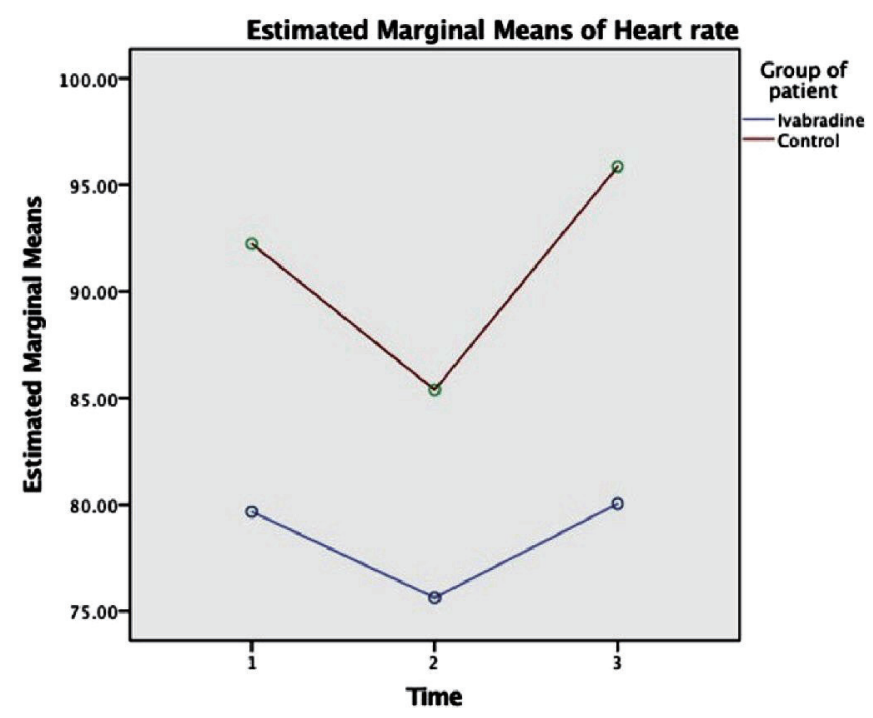
Covariates appearing in the model are evaluated at the following values: Heart rate Baseline $=$
82.820

Figure 1. Variation of heart rate (beat/min) between the groups over time (intervention time: period of each event, namely, intubation [1], incision [2] and extubation [3]) using RMANOVA analysis ( $n=25$ each). Circle indicates the mean value; corresponding SD of each mean is as follow: ivabradine group: Time (1): \pm 11.6 , Time (2): \pm 10.66 , Time (3): \pm 11.65 ; control group: Time (1): \pm 12.9 , Time (2): \pm 11.68 , Time (3): \pm 8.55 . Significance level between the groups: $P<0.005$.

tically significant association of type of intervention (ivabradine vs. control) with HR (likelihood ratio = 8.541, $\mathrm{P}=0.014$; using Chi-square tests). Mean levels of SBP, DBP and MAP during incision and operative hours were used for categorizing into groups of hypotension $(<90 / 50 / 65)$ and hypertension $(>$ $140 / 85 / 105)$.
There was no association of BP category with type of intervention as observed during cross-tabulation using Chi-square test $(\mathrm{P}=0.733$, not significant). There was no major side effect found that could be attributed to study drug. The previously established drug such as $\beta$-adrenergic blockers used for lowering BP reported of several side effects in addition to reducing

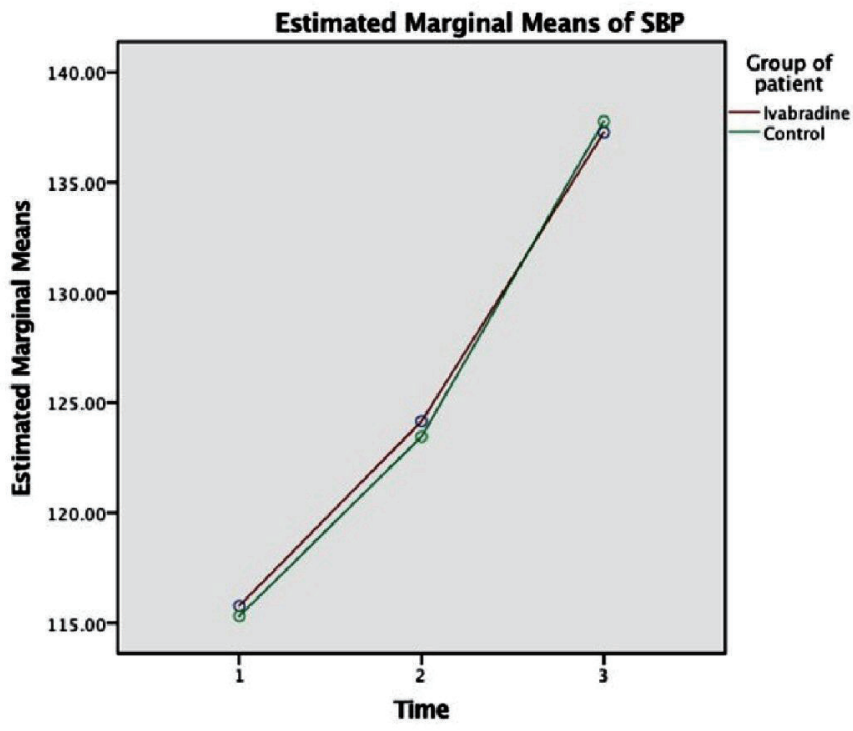

Covariates appearing in the model are evaluated at the following values: SBP Baseline $=126.46$

Figure 2. Variation of SBP $(\mathrm{mm} \mathrm{Hg})$ between the groups over time (intervention time: period of each event, namely, intubation [1], incision [2] and extubation [3]) using RMANOVA analysis ( $n=25$ each). Circle indicates the mean value. Corresponding SD of each mean is as follow: ivabradine group: Time (1): \pm 14 , Time (2): \pm 12 , Time (3): \pm 20.331 ; control group: Time (1): \pm 19 , Time (2): \pm 13 , Time (3): \pm 18.84 . Significance level between the groups: $P<0.005$. SBP: systolic blood pressure; SD: standard deviation. 


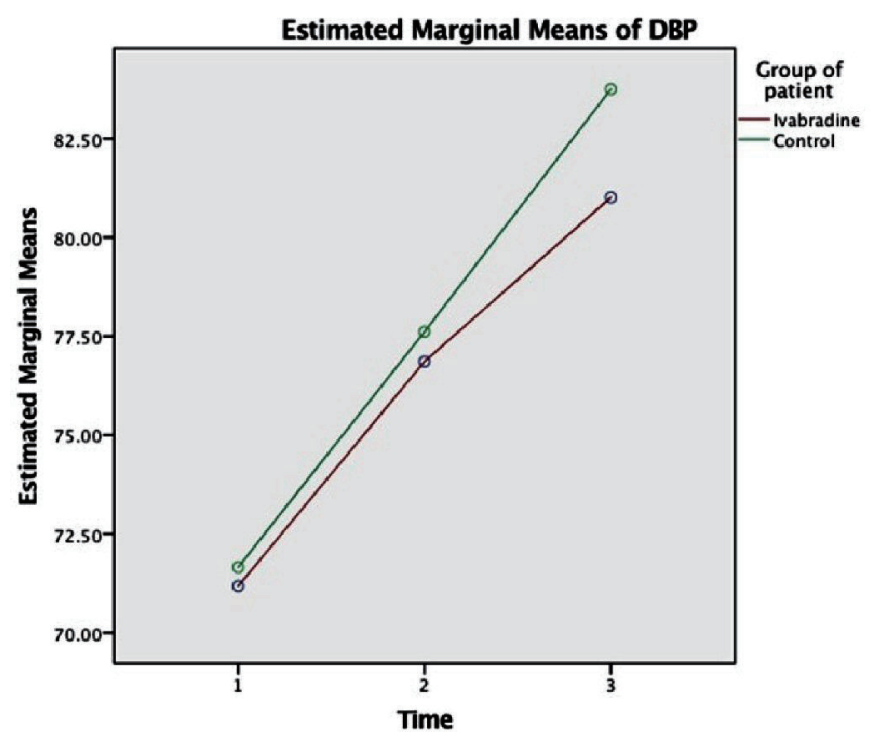

Covariates appearing in the model are evaluated at the following values: DBP Baseline $=80.560$

Figure 3. Variation of DBP $(\mathrm{mm} \mathrm{Hg})$ between the groups over time (intervention time: period of each event, namely, intubation [1], incision [2] and extubation [3]) using RMANOVA analysis ( $n=25$ each). Circle indicates the mean value. Corresponding SD of each mean is as follow: ivabradine group: Time (1): \pm 7.07 , Time (2): \pm 7.43 , Time (3): \pm 8.41 ; control group: Time (1): \pm 11.7, Time (2): \pm 9.50 , Time (3): \pm 10.699. Significance level between the groups: $P<0.005$. DBP: diastolic blood pressure; SD: standard deviation.

HR including the deterioration of peripheral vascular disease, psychological depression, bronchospasm, peripheral vasoconstriction of the extremities, hypotension and erectile dysfunction and in case of calcium channel blockers peripheral edema, hypotension and headache [43]. This makes ivabradine, good agent in view of perioperative hemodynamic stabilization. The absence of fall in BP in all above patients is an added advantage. The rise in BP seen during laryngoscopy in few patients in study group, returned to near baseline within a reasonable time. Thus, it is a definitive advantage and justification for us-

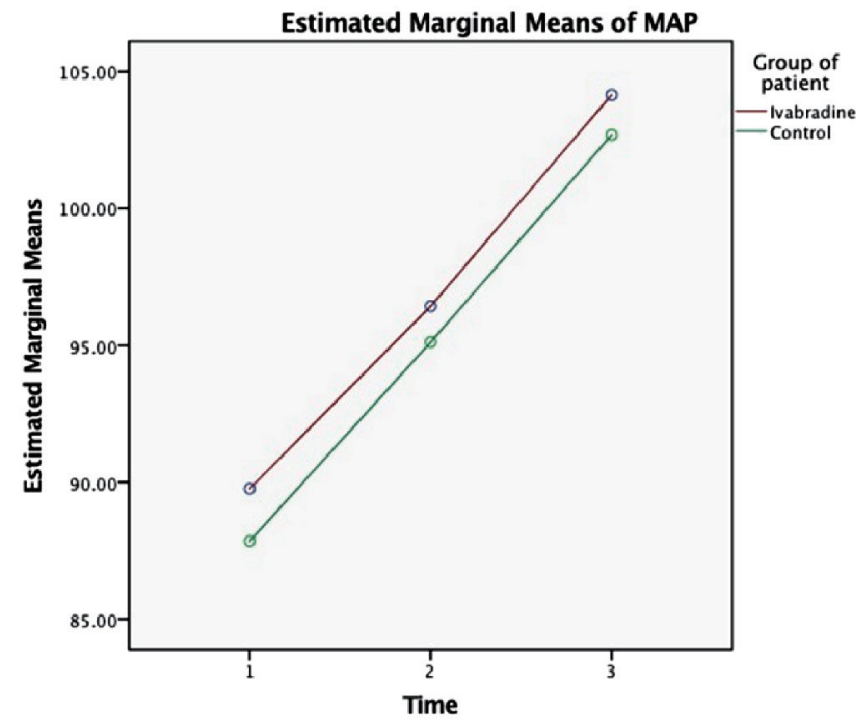

Covariates appearing in the model are evaluated at the following values: MAP Baseline $=95.8600$

Figure 4. Variation of MAP ( $\mathrm{mm} \mathrm{Hg}$ ) between the groups over time (intervention time: period of each event, namely, intubation [1], incision [2] and extubation [3]) using RMANOVA analysis ( $n=25$ each). Circle indicates the mean value. Corresponding SD of each mean is as follow: ivabradine group: Time (1): \pm 10.1 , Time (2): \pm 7.38 , Time (3): \pm 11.789 ; control group: Time (1): \pm 13.4, Time (2): \pm 10.2 , Time (3): \pm 13.84. Significance level between the groups: $P<0.005$. MAP: mean arterial pressure; SD: standard deviation. 
ing the drug in routine anesthesia practice.

In our study ivabradine has been successful in controlling the hemodynamics particularly the HR, thus, a successful agent to control stress response during perioperative period. It can safely be used in patients with diabetes and bronchial asthma with resting $\mathrm{HR} \geq 70 \mathrm{bpm}$ and either on maximum tolerated doses of $\beta$-blockers or have a contraindication to $\beta$-blocker. During the study, there were no abnormal hemodynamic responses like bradycardia, absolute bradycardia, tachycardia, hypotension, hypertension, arrhythmias, and ischemic changes.

\section{Conclusions}

Ivabradine can be used even in normotensive patients to prevent unwarranted and unwanted tachycardia witnessed during stressful intraoperative procedures like laryngoscopy, intubation, incision and extubation. Thus, preoperative oral ivabradine is safe, simple, economic and easy to administer giving a good patient compliance for a satisfactory hemodynamic control perioperatively.

\section{Acknowledgments}

I sincerely acknowledge all of the coworkers/colleagues in my institute who have helped and throughout supported this research work.

\section{Financial Disclosure}

This study is self-funded.

\section{Conflict of Interest}

None to declare.

\section{Informed Consent}

Informed consents were achieved.

\section{Author Contributions}

Dr. Anwesha Banerjee: planning, execution and analysis, as well as manuscript writing of the research work. Dr. Sangamitra Mishra: constant guidance and supervision of the research work.

\section{Data Availability}

Any inquiries regarding supporting data availability of this study should be directed to the corresponding author.

\section{References}

1. Macintosh RR. Deaths under anesthetics. Br J Anaesth. 1949;21(3):107-136.

2. Kanchi M, Nair HC, Banakal S, Murthy K, Murugesan C. Haemodynamic response to endotracheal intubation in coronary artery disease: Direct versus video laryngoscopy. Indian J Anaesth. 2011;55(3):260-265.

3. Man in't Veld AJ, Van den Meiracker AH, Schalekamp MA. Do beta-blockers really increase peripheral vascular resistance? Review of the literature and new observations under basal conditions. Am J Hypertens. 1988;1(1):9196.

4. Fabiana Aparecida Penachi Bosco, Jose Reinaldo Cerqueira Braz. Beta-blockers in anesthesiology: clinical and pharmacological aspects. Rev Bras Anestesiol. 2001;51(5):431-447.

5. Bowcock E, Morris I, Lane A. Dexmedetomidine for acute clonidine following intrathecal pump removal: A drug beginning to find its expanding niche. J Intensive Care Soc. 2016;17(3):271-272.

6. Lachaine J, Beauchemin C. Economic evaluation of dexmedetomidine relative to midazolam for sedation in the intensive care unit. Can J Hosp Pharm. 2012;65(2):103110.

7. Tse S, Mazzola N. Ivabradine (Corlanor) for heart failure: the first selective and specific if inhibitor. P T. 2015;40(12):810-814.

8. Das D, Savarese G, Dahlstrom U, Fu M, Howlett J, Ezekowitz JA, Lund LH. Ivabradine in heart failure: the representativeness of SHIFT (Systolic heart failure treatment with the if inhibitor ivabradine trial) in a broad population of patients with chronic heart failure. Circ Heart Fail. 2017;10(9):e004112.

9. Steg P, Lopez-de-Sa E, Schiele F, Hamon M, Meinertz T, Goicolea J, Werdan K, et al. Safety of intravenous ivabradine in acute ST-segment elevation myocardial infarction patients treated with primary percutaneous coronary intervention: a randomized, placebo-controlled, doubleblind, pilot study. Eur Heart J Acute Cardiovasc Care. 2013;2(3):270-279.

10. Barilla F, Pannarale G, Torromeo C, Paravati V, Acconcia MC, Tanzilli G, Mangieri E, et al. Ivabradine in patients with ST-elevation myocardial infarction complicated by cardiogenic shock: a preliminary randomized prospective study. Clin Drug Investig. 2016;36(10):849-856.

11. Kurtoglu E, Balta S, Karakus Y, Yasar E, Cuglan B, Kaplan O, Gozubuyuk G. Ivabradine improves heart rate variability in patients with nonischemic dilated cardiomyopathy. Arq Bras Cardiol. 2014;103(4):308-314.

12. Bonnet D, Berger F, Jokinen E, Kantor PF, Daubeney PEF. Ivabradine in children with dilated cardiomyopathy and symptomatic chronic heart failure. J Am Coll Cardiol. 2017;70(10):1262-1272.

13. Mengesha HG, Tafesse TB, Bule MH. If channel as an emerging therapeutic target for cardiovascular diseases: a review of current evidence and controversies. Front Pharmacol. 2017;8:874. 
14. Li N, Csepe TA, Hansen BJ, Dobrzynski H, Higgins RS, Kilic A, Mohler PJ, et al. Molecular mapping of sinoatrial node HCN channel expression in the human heart. Circ Arrhythm Electrophysiol. 2015;8(5):1219-1227.

15. Francesco Trotta. Discrepancies between observational studies and randomized controlled trials. Focus Farmacovigilanza. 2012;73(11):1.

16. Smith AJ, Goodman NW. The hypertensive response to intubation. Do researchers acknowledge previous work? Can J Anaesth. 1997;44(1):9-13.

17. Forbes AM, Dally FG. Acute hypertension during induction of anaesthesia and endotracheal intubation in normotensive man. Br J Anaesth. 1970;42(7):618-624.

18. King BD, Harris LC, Jr., Greifenstein FE, Elder JD, Jr., Dripps RD. Reflex circulatory responses to direct laryngoscopy and tracheal intubation performed during general anesthesia. Anesthesiology. 1951;12(5):556-566.

19. Tomori Z, Widdicombe JG. Muscular, bronchomotor and cardiovascular reflexes elicited by mechanical stimulation of the respiratory tract. J Physiol. 1969;200(1):2549.

20. Reid LC, Brace DE. Irritation of respiratory tract and its reflex effect on heart-Surgery. Gynaecology Obstetrics. 1940;70:157-162.

21. Burstein CL, Lo PF, Newman W. Electrocardiographic studies during endotracheal intubation. I. Effects during usual routine technics. Anesthesiology. 1950;11(2):224237.

22. Edmonds GW, Comer WH, et al. Intravenous use of procaine in general anesthesia. J Am Med Assoc. 1949;141(11):761-767.

23. Burstein CL, Zaino G, Newman W. Electrocardiographic studies during endotracheal intubation. III. Effects during general anesthesia and intravenous diethylaminoethanol. Anesthesiology. 1951;12(4):411-419.

24. Prys-Roberts C, Greene LT, Meloche R, Foex P. Studies of anaesthesia in relation to hypertension. II. Haemodynamic consequences of induction and endotracheal intubation. Br J Anaesth. 1971;43(6):531-547.

25. Fox EJ, Sklar GS, Hill CH, Villanueva R, King BD. Complications related to the pressor response to endotracheal intubation. Anesthesiology. 1977;47(6):524-525.

26. Takeshima K, Noda K, Higaki M. Cardiovascular response to rapid anesthesia induction and endotracheal intubation. Anesth Analg. 1964;43:201-208.

27. Masson AH. Pulmonary Edema during or after Surgery. I. Anesth Analg. 1964;43:440-445.

28. Hood. Using of nitroglycerine in preventing the hypertensive response to tracheal intubation in severe pre-eclampsia. Anaesthesiology. 1963.

29. Johnsson G, Regardh CG. Clinical pharmacokinetics of beta-adrenoreceptor blocking drugs. Clin Pharmacokinet.
1976;1(4):233-263.

30. Beattie WS, Wijeysundera DN, Karkouti K, McCluskey S, Tait G. Does tight heart rate control improve beta-blocker efficacy? An updated analysis of the noncardiac surgical randomized trials. Anesth Analg. 2008;106(4):10391048, table of contents.

31. Ghodki PS, Thombre SK, Sardesai SP, Harnagle KD. Dexmedetomidine as an anesthetic adjuvant in laparoscopic surgery: An observational study using entropy monitoring. J Anaesthesiol Clin Pharmacol. 2012;28(3):334-338.

32. Hall JE, Uhrich TD, Barney JA, Arain SR, Ebert TJ. Sedative, amnestic, and analgesic properties of small-dose dexmedetomidine infusions. Anesth Analg. 2000;90(3):699705.

33. Borer JS, Tardif JC. Efficacy of ivabradine, a selective I(f) inhibitor, in patients with chronic stable angina pectoris and diabetes mellitus. Am J Cardiol. 2010;105(1):2935.

34. Murat SN, Orcan S, Akdemir R, Dogan M, Kara E, Balci $\mathrm{M}$. Arrhythmic effects of ivabradine in patients with coronary artery disease. Clin Invest Med. 2009;32(5):322.

35. Swedberg K, Komajda M, Bohm M, Borer JS, Ford I, Dubost-Brama A, Lerebours G, et al. Ivabradine and outcomes in chronic heart failure (SHIFT): a randomised placebo-controlled study. Lancet. 2010;376(9744):875885.

36. Apipan B, Rummasak D. Efficacy and safety of oral propranolol premedication to reduce reflex tachycardia during hypotensive anesthesia with sodium nitroprusside in orthognathic surgery: a double-blind randomized clinical trial. J Oral Maxillofac Surg. 2010;68(1):120-124.

37. DiFrancesco D. The role of the funny current in pacemaker activity. Circ Res. 2010;106(3):434-446.

38. Ali L, Mushtaq R. Laryngoscopy and tracheal intubation. The Professional Medical Journal. 2005;12(03):267-272.

39. Shribman AJ, Smith G, Achola KJ. Cardiovascular and catecholamine responses to laryngoscopy with and without tracheal intubation. Br J Anaesth. 1987;59(3):295299.

40. Arora S, Kulkarni A, Bhargava AK. Attenuation of hemodynamic response to laryngoscopy and orotracheal intubation using intravenous clonidine. J Anaesthesiol Clin Pharmacol. 2015;31(1):110-114.

41. Gotiwale K, Lele S, Setiya S. Stress response to laryngoscopy and ease of intubation: Comparison between macintosh and (levering) McCoys type laryngoscope. Int J Res Med Sci. 2016;4:3141-3145.

42. Dutton RP. Haemostatic resuscitation. Br J Anaesth. 2012;109(Suppl 1):i39-i46.

43. Muller-Werdan U, Stockl G, Werdan K. Advances in the management of heart failure: the role of ivabradine. Vasc Health Risk Manag. 2016;12:453-470. 